Received: 15.01 .2020

Revised: 12.02 .2020

Accepted: 06.03.2020

DOI: $10.17804 / 2410-9908.2020 .2 .006-018$

\title{
BRITTLE FRACTURE RESISTANCE AND DAMPING PROPERTIES OF A STEEL-RUBBER METAL-POLYMER COMPOSITE
}

S. V. Gladkovsky ${ }^{\text {a) }}$, P. D. Nedzvetsky ${ }^{\text {b) }}$, D. I. Vichuzhanin ${ }^{\text {c) }}$, S. V. Kuteneva ${ }^{\text {d) }}$, and S. V. Lepikhin ${ }^{\mathrm{e}}$

a) (iD http://orcid.org/0000-0002-3542-6242 gsv@imach.uran.ru;

b) iD http://orcid.org/0000-0001-8546-5496 paveltag777@ gmail.com;

c) iD http://orcid.org/0000-0002-6508-6859 mmm@imach.uran.ru;

d) (iD http://orcid.org/0000-0003-4503-5488 esv@imach.uran.ru;

e) (iD http://orcid.org/0000-0002-0240-2164 lsv@imach.uran.ru

Institute of Engineering Science, Ural Branch of the Russian Academy of Sciences, 34, Komsomolskaya St., Ekaterinburg, Russian Federation

*Corresponding author. E-mail: gsv@imach.uran.ru

Address for correspondence: ul. Komsomolskaya, 34, 620049, Ekaterinburg, Russian Federation Tel.: +7 (343) 36234 48; fax: +7 (343) 3745330

The results of comparative tests for impact bending of 09G2S steel specimens and a coldglued 3-layer "09G2S steel-1F-1-HFAA-C rubber" composite show that, unlike the base steel, the metal-polymer composite retains increased values of impact strength $\mathrm{KCV}$ at temperatures ranging from 20 to $-60{ }^{\circ} \mathrm{C}$. The high level of the brittle fracture resistance of the steel-rubber composite under dynamic loading conditions at low temperatures results from the development of the delamination toughening effect characteristic of layered materials. The 100-cycle alternating tests and processing of their results have made it possible to construct mechanical hysteresis loops for the steel base and the metal-polymer composite and to determine the main parameters governing the damping capacity of the materials (the values of the mechanical loss angle tangent and the components of the complex elastic modulus). The possibility of using the metal-polymer composite under study, which is highly resistant to brittle fracture at low climatic temperatures, in highly vibration-resistant structural components of transport systems is demonstrated.

Keywords: low-carbon steel, frost-resistant rubber, microstructure, impact strength, mechanical hysteresis loops, dynamic-mechanical analysis, damping properties.

\section{Acknowledgment}

We appreciate the assistance of $V$. G. Starkov (IES UB RAS) in making composite material specimens.

The work was done with the use of the equipment installed at the Plastometriya collective use center affiliated to the IES UB RAS; it was performed under the state assignment for the IES UB RAS, theme No. AAAA-A18-118020790147-4 and supported by UB RAS project No. 18-9-1-20 (the Arctic program).

\section{References}

1. Gladkovsky S.V. Kuteneva S.V., Kamantsev I.S., Galeev R.M., Sergeev S.N., Dvoynikov D.A. Formation of the Mechanical Properties and Fracture Resistance Characteristics of Sandwich Composites Based on the 09G2S Steel and the EP678 High-Strength Steel of Various Dispersion. 
Diagnostics, Resource and Mechanics of materials and structures, 2017, iss. 6, pp. 71-90. DOI: 10.17804/2410-9908.2017.6.071-090.

2. Gladkovskii S.V., Kamantsev I.S., Kuteneva S.V., Dvoynikov D.A., Kuznetsov A.V. Layered Metal Composites with High Resistance to Brittle Fracture at Low Temperatures. AIP Conference Proceedings, 2018, vol. 2053, 020003. DOI: 10.1063/1.5084349.

3. Gladkovsky S.V., Kuteneva S.V., Sergeev S.N. Microstructure and mechanical properties of sandwich copper/steel composites produced by explosive welding. Materials Characterization, 2019, vol. 154, pp. 294-303. DOI: 10.1016/j.matchar.2019.06.008.

4. Chawla K.N. Composite Materials Science and Engineering, 4th ed., Department of Materials Science and Engineering, The University of Alabama at Birmingham, Birmingham, USA, 2019, 557 p. DOI: 10.1007/978-3-030-28983-6.

5. Kablov E.N. Innovative developments of FSUE "VIAM" SSC RF on the implementation of "Strategic directions for the development of materials and technologies for their processing for the period up to 2030". Aviatsionnye Materialy i Tekhnologii, 2015, no. 1 (34), pp. 3-33 DOI: 10.18577/2071-9140-2015-0-1-3-33. (In Russian).

6. Meure S., Varley R.J., Dong Yang Wu, Mayo S., Nairn K., Furman S. Confirmation of the healing mechanism in a mendable EMAA-epoxy resin. European Polymer Journal, 2012, vol. 48, pp. 524-531. DOI: 10.1016/j.eurpolymj.2011.11.021.

7. Chernikov S.A. Expansion of the suppression band of a vibroprotective system by a feedback dynamic damper. Journal of Machinery Manufacture and Reliability, 2015, vol. 44, no. 5, pp. 439-444. DOI: 10.3103/S1052618815050052.

8. Ponomarev Yu.K. and Ulanov A.M. Comparison of Russian and Foreign Vibration Insulators Made of Wire Damping Materials. Izv. SNTs RAN, 2009, vol. 11, no. 3, pp. 214-218. (In Russian).

9. Tipalin S.A., Saprytkin B.Yu., Shpunkin N.F. Overview of the multi-layer sheet deformable materials for protection against noise. Izvestiya $M G T U$ «MAMI», 2012, no. 2, pp. 194-199. (In Russian).

10. Kolodkin M.N., Zaytsev A.A. Long-range designs for underground rail tracks. Transport Rossiyskoy Federatsii, 2012, nos. 40-41, pp. 74-76. (In Russian).

11. Verbilov A.F., Kovalev V.V., Ulrich S. A. Nonlinear oscillation processes in the dynamics of the caterpillar drive with rubber-metal pin joint. Izvestiya Samarskogo Nauchnogo Tsentra Rossiyskoy Akademii Nauk, 2018, no. 6, pp. 243-247. (In Russian).

12. Antipov V.V., Chesnokov D.V., Kozlov I.A., Volkov I.A., Petrova A.P. Surface preparation aluminum alloy V-1469 before use in the composition of layered hybrid material. Trudy VIAM, 2018, no. 64, pp. 59-65. DOI: 10.18577 / 2307-6046-2018-0-4-59-65. (In Russian).

13. Sagomonova V.A., Kislyakova V.I., Tyumeneva T.Yu., Bolshakov V.A. The influence of vibration damping materials' composition on their mechanical loss factor. In: Trudy VIAM, 2015, no. 10, pp. 63-69. (In Russian).

14. Sytyj Yu.V., Sagomonova V.A., Kislyakova V.I., Bol'shakov V.A. Novel vibroabsorbing materials. In: Trudy VIAM, 2012, no. 3, pp. 51-54 (In Russian).

15. Ponomarev Y.K., Ulanov A.M. Comparison of Russian and Foreign Vibration Insulators Made of Wire Damping Materials. Izv. SNTs RAN, 2009, vol. 11, no. 3, pp. 214-218. (In Russian).

16. Solomatov V.I., Cherkasov V.D., Fomin N.E. Vibropogloshchayushchie kompozitsionnye materialy [Vibration absorbing composite materials]. Saransk, Izd-vo Mordovskogo un-ta Publ., 2001, 95 p. (In Russian).

17. Embury J.D., Petch N.J, Wright E.S. Fracture of mild steel laminates. Transactions of the Society of Mining Engineers of AIME, 1967, vol. 239 (1), pp. 114-18.

18. Babinsky K., Primig S., Knabl W., Lorich A., Stickler R., Clemens H. Fracture Behavior and Delamination Toughening of Molybdenum in Charpy Impact Tests. Journal of the Minerals Metals \& Materials Society, 2016, vol. 68, iss. 11, pp. 2854-2863. DOI: 10.1007/s11837-016-2075-y. 
Подана в журнал: 15.01 .2020

УДК 621.792.4-053:620.178.746.22:539.67

DOI: $10.17804 / 2410-9908.2020 .2 .006-018$

\title{
СОПРОТИВЛЕНИЕ ХРУПКОМУ РАЗРУШЕНИЮ И ДЕМПФИРУЮЩИЕ СВОЙСТВА МЕТАЛЛОПОЛИМЕРНОГО КОМПОЗИТА ТИПА «СТАЛЬ-РЕЗИНА»
}

\author{
С. В. Гладковский ${ }^{\mathrm{a})^{*}}$ П. Д. Недзвецкийб), Д. И. Вичужанинн ${ }^{\mathrm{B}}$, \\ С. В. Кутенева ${ }^{\text {г) }}$, С. В. Лепихин ${ }^{\text {I) }}$ \\ Федеральное государственное бюджетное учреждение науки Институт машиноведения \\ Уральского отделения Российской академии наук, \\ 34, ул. Комсомольская, г. Екатеринбург, 620049, Российская Федераџия \\ a) iD http://orcid.org/0000-0002-3542-6242 gsv@imach.uran.ru; \\ б) (iD http://orcid.org/0000-0001-8546-5496 paveltag777@gmail.com; \\ в) (iD http://orcid.org/0000-0002-6508-6859 mmm@imach.uran.ru; \\ г) (iD http://orcid.org/0000-0003-4503-5488 esv @imach.uran.ru; \\ д) (iD http://orcid.org/0000-0002-0240-2164 1sv@imach.uran.ru \\ * Ответственный автор. Электронная почта: gsv@imach.uran.ru \\ Адрес для переписки: ул. Комсомольская, 34, г. Екатеринбург, Российская Федерация \\ Тел.: +7 (343) 362-42-17, факс: +7 (343) 374-53-30
}

По результатам сравнительных испытаний на ударный изгиб образцов из стали 09Г2С и полученного методом холодного склеивания 3-слойного композита «Сталь 09Г2С-резина 1Ф-1-ТМКЩ-С» сделан вывод, что в отличие от стали основы металлополимерный композит сохраняет повышенные значения ударной вязкости KCV в интервале температур от +20 до $-60{ }^{\circ} \mathrm{C}$. Высокий уровень сопротивления хрупкому разрушению композита типа «сталь-резина» в условиях динамического нагружения при пониженных температурах связывается с проявлением характерного для материалов со слоистым строением эффекта «вязкости расслоения». Проведенные знакопеременные циклические испытания на базе 100 циклов и обработка их результатов позволили построить для стали основы и металлополимерного композита петли механического гистерезиса и оценить основные параметры, определяющие демпфирующую способность изученных материалов (значения тангенса угла механических потерь и компонент комплексного модуля упругости). Показана возможность использования изученного слоистого композита, обладающего повышенным сопротивлением хрупкому разрушению в области низких климатических температур, а также в элементах конструкций транспортных систем с высокой вибрационной стойкостью.

Ключевые слова: слоистый композит, низкоуглеродистая сталь, морозостойкая резина микроструктура, ударная вязкость, петли механического гистерезиса, динамический механический анализ, демпфирующие свойства.

\section{1. Введение}

Широкое применение в авиастроительной, космической и автомобилестроительной областях находят металлополимерные композиционные материалы [1-6]. Данные композиты обладают низкой плотностью, высокой удельной жесткостью и прочностью, повышенной стойкостью в агрессивных средах, обладают одновременно и ярко выраженными вязкоупругими свойствами, что позволяет применять их в качестве вибродемпфирующих элементов и отказаться от создания специализированных систем демпфирования [7-10]. Придание особых свойств материалам, таких как повышенные диссипативные свойства, позволят успешно 
применять их в области транспортных систем. В этом случае демпфирующая способность композиционных материалов рассматривается не как второстепенный эффект, а как один из основных параметров проектирования [11]. Значительный практический интерес представляет одна из разновидностей металлополимерных композиционных материалов - слоистые композиты типа «сталь-резина». Одним из основных способов, применяемых для получения композитов данного типа, является метод холодного клеевого соединения [12]. Применение композиционных материалов на основе металлов и резины возможно в области строительства железнодорожных дорог для высокоскоростных перевозок [10]. В связи с этим наше исследование посвящено изучению характеристик ударной вязкости при комнатной и пониженных температурах, а также демпфирующих свойств слоистых клееных композиционных материалов на основе стали 09Г2С с прослойками из морозостойкой резины 1Ф-1-ТМКЩ-С.

\section{2. Материалы и методы исследования}

Для изготовления клееного композита были выбраны полосы из резины 1Ф-1-ТМКЩ-С различной толщины, химический состав и механические свойства которой соответствовали ГОСТ 7338-90. Согласно указанному ГОСТу резина была поставлена в форме пластин 1-го класса, вида Ф, типа I, марки ТМКЩ, степени твердости С. Температурные интервалы эксплуатации и механические свойства этой резины представлены в табл. 1. Выбор резины в составе композита определялся достаточно широким интервалом рабочих температур, а также с возможностью сохранения свойств резины в агрессивных средах. Резина марки ТМКЩ относится к классу тепломорозокислотощелочестойких.

Таблица 1 - Рабочие температуры и механические свойства полос резины 1Ф-1-ТМКЩ-С согласно ГОСТ 7338-90

\begin{tabular}{|c|c|c|c|c|}
\hline $\begin{array}{c}\text { Марка } \\
\text { резины }\end{array}$ & Температурный интервал, ${ }^{\circ} \mathrm{C}$ & $\sigma_{\text {в }}$, МПа & $\delta, \%$ & $\begin{array}{c}\text { Твердость } \\
\text { по Шору }\end{array}$ \\
\hline ТМКЩ & От -60 до +80 & 5 & 250 & $50-65$ \\
\hline
\end{tabular}

Исходные полосы 09Г2С были обрезаны под размеры образцов для испытаний на удар и растяжение-сжатие. Химический состав стали 09Г2С был определен на оптическом эмиссионном спектрометре SPECTROMAXx (табл. 2). Исходные полосы из стали 09Г2C подвергались предварительной нормализации (нагреву выше точки $\mathrm{Ac}_{3}$ до температуры $920{ }^{\circ} \mathrm{C}$, выдержке 1 ч и последующему охлаждению на воздухе).

Таблица 2 - Химический состав стали 09Г2С, используемой для создания композита

\begin{tabular}{|c|c|c|c|c|c|c|c|c|c|}
\hline \multicolumn{10}{|c|}{ Содержание элементов, мас. \% } \\
\hline $\mathrm{C}$ & $\mathrm{Si}$ & $\mathrm{Mn}$ & $\mathrm{Cr}$ & $\mathrm{Ni}$ & $\mathrm{Mo}$ & $\mathrm{Al}$ & $\mathrm{Cu}$ & $\mathrm{S}$ & $\mathrm{P}$ \\
\hline 0,12 & 0,68 & 1,32 & 0,07 & 0,07 & 0,01 & 0,04 & 0,12 & 0,01 & 0,02 \\
\hline
\end{tabular}

Микроструктуру исходной стали 09Г2С исследовали с помощью оптического микроскопа NEOPHOT-21 при увеличении $\times 800$. Травление микрошлифа проводилось химическим способом в 3 \%-м спиртовом растворе азотной кислоты. Испытания на растяжение стали 09Г2С проводили при комнатной температуре на универсальной испытательной машине INSTRON8801 в соответствии с рекомендациями ГОСТ 1497-84 на плоских образцах типа I толщиной 5 мм.

Для склеивания слоев композита был использован клей на основе эпоксидной смолы с добавлением специальных биофункциональных соединений, что обеспечило сохранение повышенной прочности сцепления слоев в диапазоне температур от +20 до $-60{ }^{\circ} \mathrm{C}$. 
Перед склеиванием полосы 09Г2С были очищены, обезжирены, обработаны пескоструйной обработкой и протравлены в течение 15-20 мин при температуре $70-75{ }^{\circ} \mathrm{C}$ раствором из 3,5 весовых частей бихромата натрия в 3,5 весовых частей дистиллированной воды и 200 весовых частей концентрированной серной кислоты. После травления поверхность была тщательно промыта водой и высушена. Заранее вулканизированные полосы из резины обрезаны под размер образцов для испытаний на удар и растяжение-сжатие. Затем поверхность резины была обезжирена с целью удаления талька, а также масел. После подготовки поверхности на нее был нанесен клей с размешанным отвердителем. После процесса склеивания образцы были оставлены до полного высыхания клея при комнатной температуре в течение 2 суток. В результате склеивания были получены 3-слойные образцы композитов с содержанием резины 1Ф-1-ТМКЩ-С $20 \%$. Схема сборки композита представлена на рис. 1.

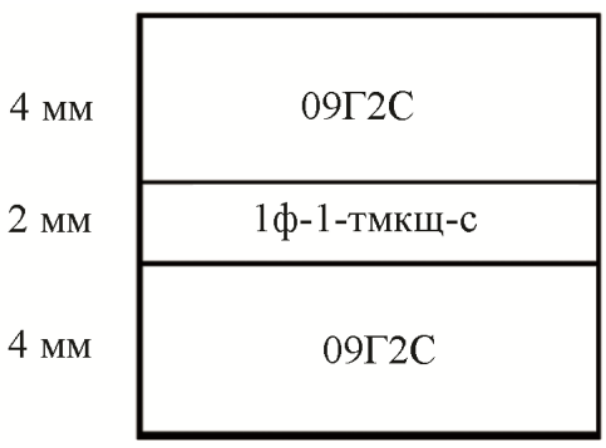

Рис. 1. Схема укладки слоев 3-слойного композита на основе стали 09Г2С и резины 1Ф-1-ТМКЩ-С. Цифрами слева отмечена толщина слоев в миллиметрах. Методика получения соединения - холодное склеивание

Испытания на ударную вязкость проводились при температурах +20 и -60 С на инструментированном маятниковом копре IT 542M фирмы «Tinius Olsen» на стандартных образцах типа 11 размером $10 \times 10 \times 55$ мм с V-образным надрезом по «тормозящему типу». Разброс полученных значений не превышал 5 \%. Фрактографический анализ поверхности изломов композита после механических испытаний проводили на растровом электронном микроскопе TESCAN VEGA II XMU.

Метод динамического механического анализа (ДМА) [13-16] позволяет получить информацию об изменении таких характеристик, как тангенс угла механических потерь $(\operatorname{tg} \delta)$, компонент комплексного модуля упругости (модуль упругости (E'), модуль вязкости (Е")) под воздействием периодической, синусоидальной динамической нагрузки [13]. Данные характеристики определяют демпфирующую способность материалов. Определение характеристик демпфирования материалов при растяжении-сжатии регламентировано стандартом DIN 53513. Оценка демпфирующей способности образцов слоистых металлополимерных материалов проводилась на плоских образцах стали основы (09Г2С) и 3-слойного металлополимерного композита (сталь 09Г2С - резина 1Ф-1-ТМКЩ-С) типа 1, выполненных в соответствии с ГОСТ 1497-84. Образцы имели толщину и ширину рабочей части 10 и 15 мм соответственно при общей длине, равной 130 мм. Испытание проводили при комнатной температуре на универсальной испытательной машине INSTRON8801, оснащенной лазерным датчиком деформации, замеры которого обрабатывались программой Console. Разброс экспериментальных значений механических характеристик не превышал $\pm 2,5 \%$. Образцы подвергались знакопеременному циклическому нагружению синусоидального типа по жесткой схеме (в режиме контроля по деформации), с частотой 1 Гц и коэффициентом асимметрии цикла $\mathrm{R}=$ -1 . Количество циклов нагружения составляло $\mathrm{N}=100$ циклов. Для проведения циклических испытаний задавалась максимальная величина напряжения ( $\sigma \leq 305 \mathrm{MПа})$, деформация 0,2 мм и амплитуда деформации $\pm 0,5$ мкм. 


\section{3. Результаты и обсуждение}

При изучении исходных полос стали 09Г2С в нормализованном состоянии было установлено, что 09Г2С имеет феррито-перлитную структуру (рис. 2) в соотношении составляющих феррит:перлит 80:20. Зерна феррита имеют относительно равноосную форму, близкую к полигональной. Средний размер зерен феррита составляет 12 мкм.

Механические свойства при комнатной температуре исходных полос стали 09Г2С после нормализации, полученные при испытаниях на одноосное растяжение, приведены в табл. 3.

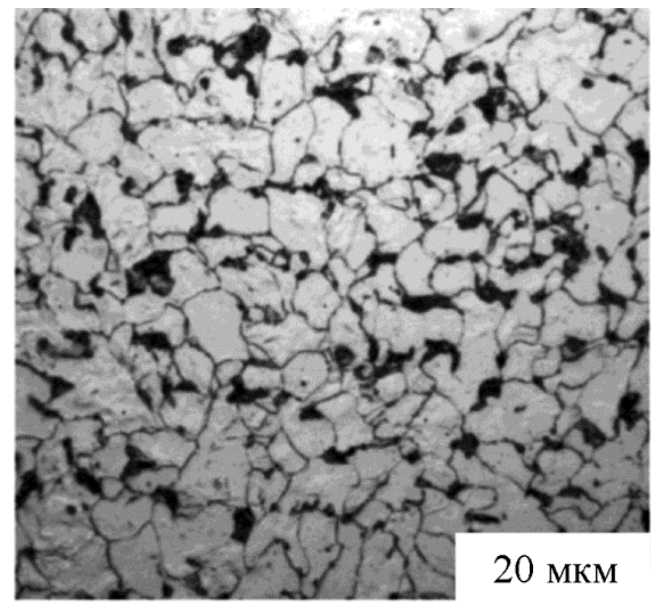

Рис. 2. Микроструктура стали 09Г2С в нормализованном состоянии

Таблица 3 - Механические свойства стали 09Г2С

\begin{tabular}{|l|c|c|c|c|}
\hline \multicolumn{1}{|c|}{ Материал } & $\sigma_{0,2}, \mathrm{MПа}$ & $\sigma_{\mathrm{B}}, \mathrm{MПа}$ & $\delta, \%$ & $\psi, \%$ \\
\hline $\begin{array}{l}\text { 09Г2С, прокат в нормализованном } \\
\text { состоянии толщиной 5 мм }\end{array}$ & 336 & 465 & 24 & 67 \\
\hline
\end{tabular}

При исследовании образцов клееного композита на основе металла и резины после ударных испытаний было установлено, что при приложении ударной нагрузки независимо от температуры испытаний наблюдается только пластический изгиб второго слоя стали 09Г2С, т. е. полного разрушения образца слоистого композита не происходит (рис. $3 a, 6$ ).

При комнатной температуре в результате ударного нагружения разрушения слоя резины и второго слоя стали 09Г2С в составе 3-слойного композита не наблюдалось (рис. 3 a). Вероятно, это связано с тем, что резина имеет свойства интенсивно поглощать энергию, приложенную к ней, тем самым предотвращая разрушение последующих слоев. Однако при этом было выявлено частичное отслоение полос стали 09Г2С. Разрушение произошло только в верхнем слое стали, что говорит о высоких ударопоглощающих свойствах резины. При понижении температуры до $-60{ }^{\circ} \mathrm{C}$ во время испытания образца композита произошло разрушение слоя 09Г2С, а также слоя резины, однако последующий слой 09Г2С не разрушился (рис. 3 б). Расслоения 3-слойного образца при пониженной температуре ударного испытания не наблюдалось. 


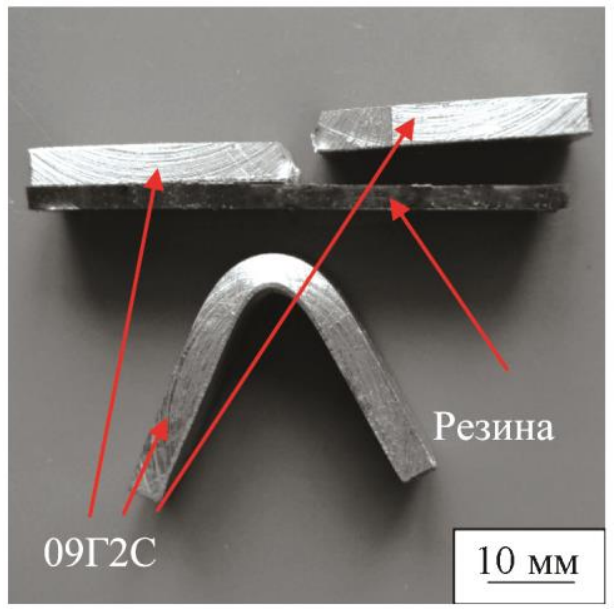

$a$

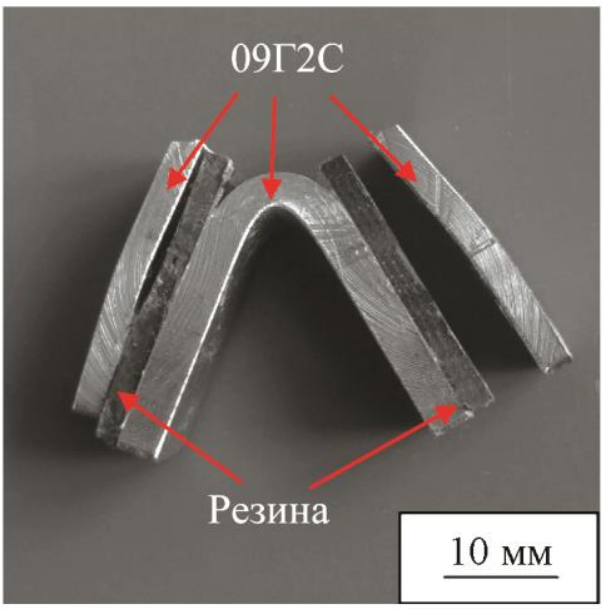

$\sigma$

Рис. 3. Боковая поверхность изломов 3-слойного клееного композита (сталь 09Г2С и резина 1Ф-1-ТМКЩ-С) после ударных испытаний при температуре: $+20{ }^{\circ} \mathrm{C}(a)$ и $-60{ }^{\circ} \mathrm{C}(\sigma)$

Как видно из приведенных в табл. 4 результатов ударных испытаний стали основы 09Г2С и 3-слойных клееных сталерезиновых композитов, понижение температуры испытаний от комнатной до $-60^{\circ} \mathrm{C}$ способствует снижению значений ударной вязкости $\mathrm{KCV}$ почти в 3 раза.

Таблица 4 - Результаты ударных испытаний образцов 3-слойного композита на основе стали 09Г2С и резины 1Ф-1-ТМКЩ-С с надрезом по тормозящему типу

\begin{tabular}{|c|c|c|}
\hline Материал & $\mathrm{T}_{\text {исп., }},{ }^{\circ} \mathrm{C}$ & $\mathrm{KCV}, \mathrm{MДж/ \textrm {M } ^ { 2 }}$ \\
\hline \multirow{2}{*}{$09 \Gamma 2 \mathrm{C}$} & 20 & 0,85 \\
\hline & -60 & 0,31 \\
\hline \multirow{2}{*}{$\begin{array}{c}\text { 3-слойный композит } \\
\text { (сталь 09Г2С + резина 1Ф-1-ТМКЩ-С) }\end{array}$} & 20 & $>0,83$ \\
\hline & -60 & $>0,67$ \\
\hline
\end{tabular}

Примечание. Образцы 3-слойного композиционного материала полностью не разрушились, поэтому ударная вязкость обозначается как $\mathrm{KCV}>$.

Это хорошо согласуется со сменой доминирующего микромеханизма разрушения стали 09Г2С с понижением температуры испытаний от вязкого ямочного к преимущественно хрупкому разрушению по механизму квазискола (рис. $4 a, 6)$. 


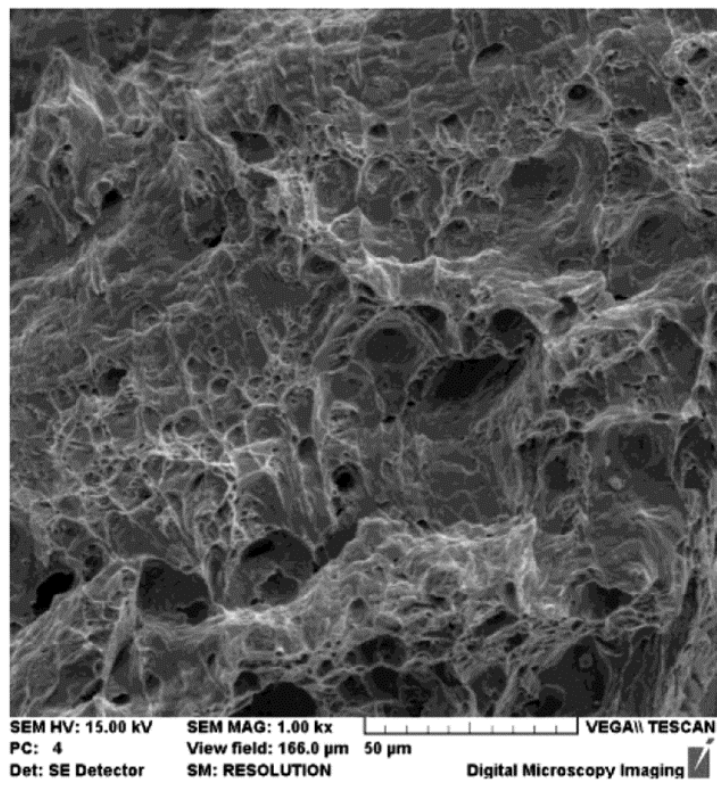

$a$

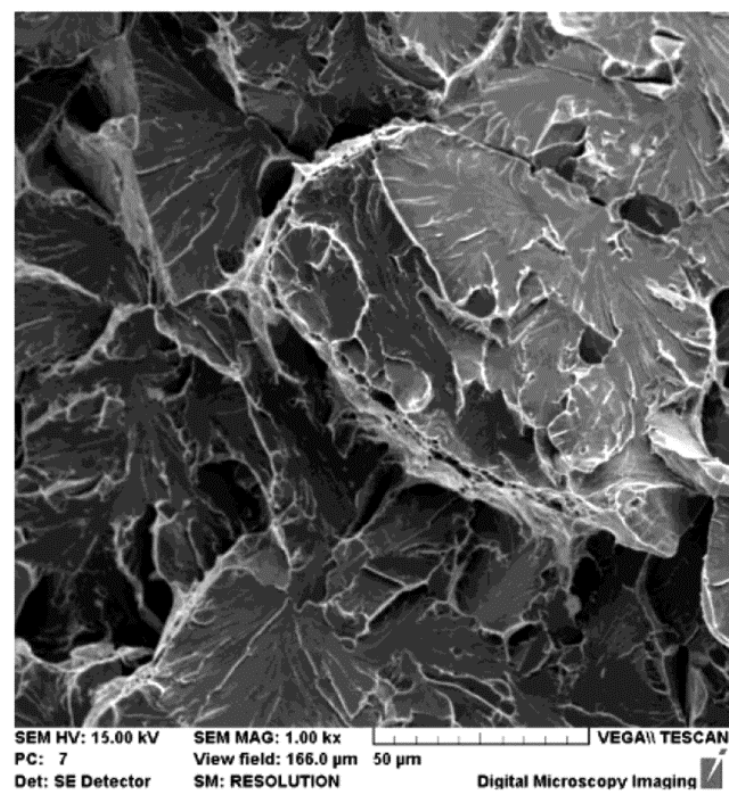

$\sigma$

Рис. 4. Микрофрактограммы слоев 09Г2С в 3-слойном композите типа «сталь-резина» после ударных испытаний при температуре $+20{ }^{\circ} \mathrm{C}(a)$ и $-60{ }^{\circ} \mathrm{C}(\sigma)$

Испытания образцов 3-слойного композита с ориентацией надреза по тормозящему типу («crack arrester») [17] выявили незначительное различие в ударной вязкости стальных и металлополимерных образцов при комнатной температуре испытаний. Вместе с тем значения KCV 3-слойного композита при понижении температуры испытаний до $-60{ }^{\circ} \mathrm{C}$ уменьшаются с 0,83 до 0,67 Дж/м ${ }^{2}$ и в низкотемпературной области соответствуют более высокому уровню ударной вязкости по сравнению с монолитными стальными образцами (табл. 4). При испытаниях в условиях пониженной температуры наблюдается значительный рост ударной вязкости композиционного материала относительно исходной стали, при этом значения $\mathrm{KCV}$ для 3-слойного композиционного материала в 2 раза выше, чем у стали. Повышению ударной вязкости металлополимерного композита способствует реализация эффекта «вязкости расслоения» («delamination toughening») [18]. Этот эффект проявляется во всех искусственных (слоистых композитах), а также естественных композиционных материалах и связан с их слоистым строением. Кроме эффекта «вязкости расслоения» в данном композиционном материале не менее значительную роль играет и пластифицирующее влияние резиновой прослойки. Важно отметить, что в процессе ударных испытаний при температуре $-60{ }^{\circ} \mathrm{C}$ произошло разрушение слоя резины в 3-слойном композите. При этом зафиксировано наибольшее значение низкотемпературной ударной вязкости KCV композита по сравнению со сталью 09Г2С. Таким образом, использование резины в многослойных слоистых композиционных материалах способствует повышению их сопротивления хрупкому разрушению в области низких климатических температурах благодаря пластифицирующей способности резины и проявлению в композите эффекта «вязкости расслоения».

После проведения циклического растяжения сжатия с нагружением по жесткому типу (с заданным размахом деформации) образцы композиционного материала сохранили свою целостность, однако наблюдались локальные отслоения резины от стали 09Г2С (рис. 5) 


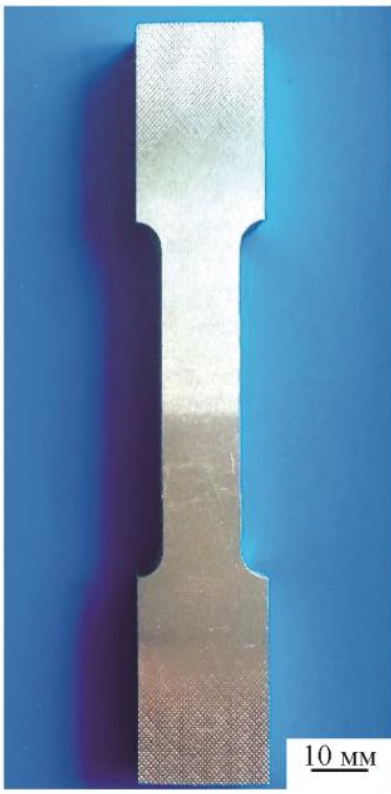

$a$

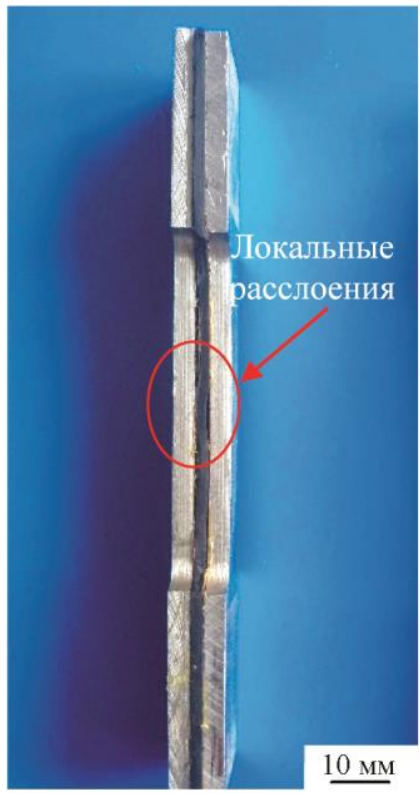

$\sigma$

Рис. 5. Фронтальный ( $a)$ и боковой (б) вид образцов 3-слойного композита после циклического нагружения

В результате знакопеременного растяжения-сжатия была получена зависимость изменения длины образца ( $\Delta \mathrm{L}, \mathrm{MM})$ от приложенной силы $(\mathrm{P}, \mathrm{\kappa H})$. Для построения петли гистерезиса приложенная сила переведена в напряжение, а изменение длины - в деформацию. После проведения преобразований были получены петли механического гистерезиса после 100 циклов растяжения, сжатия образцов из стали 09Г2С и 3-слойного клееного композита на основе стали 09Г2С с прослойками из резины 1Ф-1-ТМКЩ-С (рис. 6).

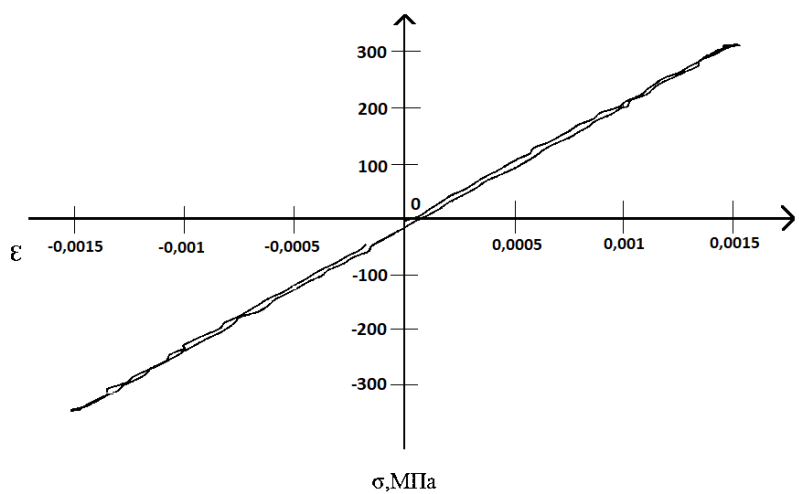

$a$

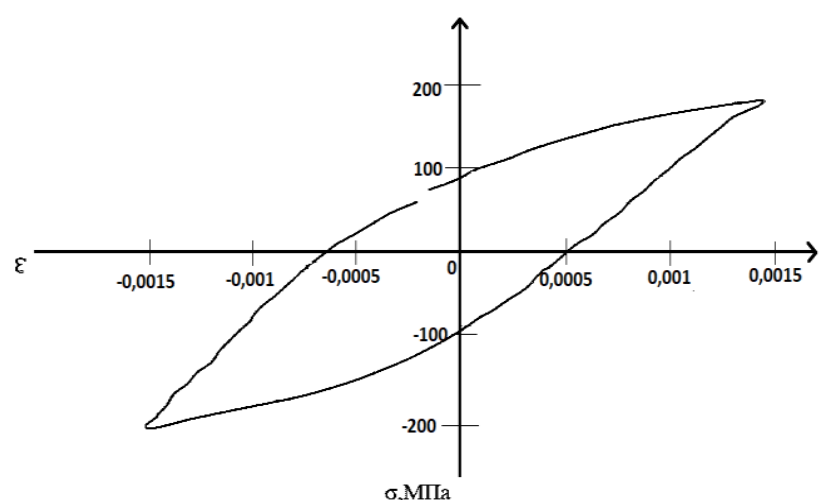

$\sigma$

Рис. 6. Петли механического гистерезиса при знакопеременном циклическом растяжениисжатии образцов стали 09Г2С (a) и 3-слойного композита (сталь 09Г2С-резина 1Ф-1-ТМКЩ-С) (б)

По петлям гистерезиса определено, что нагружение проходило ниже предела упругости $\sigma_{0,2}$ стали 09Г2С, однако в композиционном материале на основе данной стали присутствовала вязкая составляющая, что подтверждается расширением площади петли гистерезиса. Увеличение площади петли указывает на то, что энергия, поглощаемая композитом, определяющая его демпфирующую способность, выше, чем у исходной 
стали основы. Для дальнейшей оценки демпфирующих свойств по результатам обработки массива экспериментальных данных были построены синусоиды деформации и напряжения (рис. 7). Механическая нагрузка (напряжение или деформация), как отмечено выше, прикладываются синусоидально с определенной частотой, которая описывается по закону (1) [14]:

$$
\sigma=\sigma_{0} \cdot \sin \omega t
$$

где $\sigma$ - напряжение в момент времени $t ; \sigma_{0}$ - максимальное напряжение; $\omega$ - частота колебаний.

Приложенное синусоидальное напряжение имеет соответствующий ответный сигнал деформацию, который также описывается синусоидальной функцией [14]. С учетом упругого соотношения (2):

$$
\varepsilon=\mathrm{E} \sigma_{0} \sin \omega \mathrm{t}=\varepsilon_{0} \sin \omega \mathrm{t},
$$

где $\varepsilon$ - деформация в момент времени t; $\varepsilon_{0}$ - деформация, соответствующая максимальному напряжению; $\omega$ - частота колебаний; Е - модуль упругости.

При сравнении полученных синусоид деформации и нагрузки (рис. 7) определены тангенс угла механических потерь $(\operatorname{tg} \delta)$, компоненты комплексного модуля упругости (модуль упругости (Е'), модуль вязкости (E")).

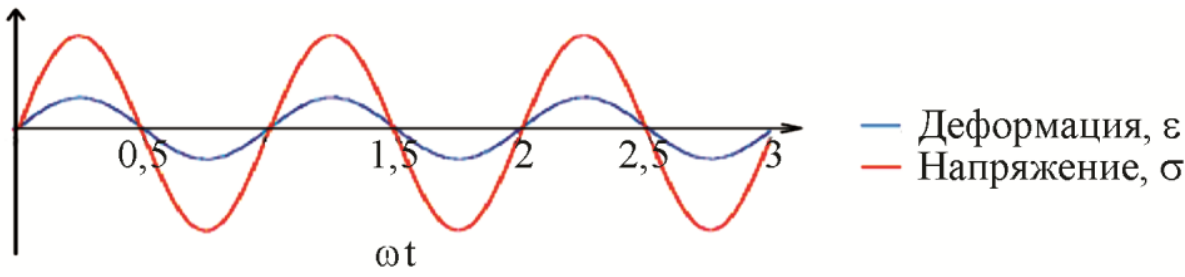

$a$

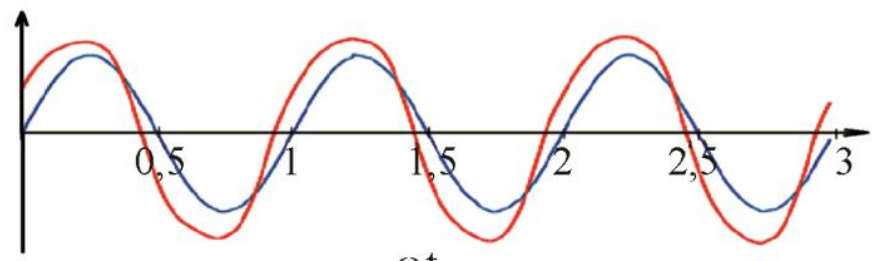

$\omega t$

б

Рис. 7. Синусоиды деформации и напряжения: для стали 09Г2С (a); 3-слойного композита 09Г2С с прослойками резины 1Ф-1-ТМКЩ-С (б)

Отклик образца 3-слойного композита при механическом нагружении по деформации относительно напряжения запаздывает во времени вследствие необратимых потерь энергии. В результате этого наблюдается фазовый сдвиг $\delta$ между приложенным напряжением и деформацией. Для оценки фазового сдвига $\delta$ между приложенным напряжением и деформацией по построенным синусоидам определена разница достижения $\varepsilon_{0}$ и $\sigma_{0}$ по времени. Выражение для деформации имеет вид (3):

$$
\varepsilon=E \sigma_{0} \sin \omega \mathrm{t}=\varepsilon_{0} \sin (\omega \mathrm{t}+\delta) .
$$


В связи с наличием фазового сдвига выражение (3) изменено и имеет вид (4):

$$
\varepsilon=\varepsilon_{0}[\sin (\omega \mathrm{t}) \cos \delta+\cos (\omega \mathrm{t}) \sin \delta]
$$

из чего следует, что деформация $\varepsilon$ может быть представлена как сумма двух составляющих модуля вязкости и модуля упругости [14]. Из формулы (4) следуют выражения для модуля упругости (5) и модуля вязкости (6):

$$
\begin{aligned}
& \mathrm{E}^{\prime}=\left(\sigma_{0} / \varepsilon_{0}\right) \cos \delta ; \\
& \mathrm{E}^{\prime \prime}=\left(\sigma_{0} / \varepsilon_{0}\right) \sin \delta .
\end{aligned}
$$

Используя приведенные выше формулы с помощью программы MS Excel, был выполнен анализ полученных данных, определены значения $\sigma_{0}$ и $\varepsilon_{0}$ для стали09Г2С и композита как максимумы графиков синусоид. Было установлено расстояние между ближайшими максимумами, которое соответствует углу сдвига фаз $\delta$. Затем по формулам (5) и (6) были определены модуль вязкости Е" и модуль упругости Е'.

При оценке представленных на рис. 7 данных можно сделать вывод о том, что для деформирования стали 09Г2С необходимо более высокое напряжение, чем для деформирования композиционного материала типа «сталь-резина». Данные, полученные при численной обработке, представлены в табл. 5.

Таблица 5 - Основные показатели вибростойкости стали 09Г2С и 3-слойного композита (сталь 09Г2С - резина 1Ф-1-ТМКЩ-С)

\begin{tabular}{|l|c|c|c|c|c|c|}
\hline \multicolumn{1}{|c|}{ Материал } & $\varepsilon_{0}$ & $\sigma_{0}, \mathrm{MПа}$ & $\delta$, град & $\mathrm{E}^{\prime}, 10^{3}, \mathrm{MПа}$ & $\mathrm{E}^{\prime \prime}, 10^{3}, \mathrm{MПа}$ & $\operatorname{tg} \delta$ \\
\hline 09Г2С & 0,0015 & 305 & 0 & 203 & 0 & 0 \\
\hline Композит & 0,0015 & 200 & 0,07 & 133 & 0,163 & 0,07 \\
\hline
\end{tabular}

Анализируя полученные данные можно отметить, что в образцах стали 09Г2С деформация и напряжение совпадали по фазе, следовательно, материал был полностью упругим и механических потерь в этом случае не наблюдалось. При изученном режиме циклического нагружения исходная сталь 09Г2С не обладает выраженными демпфирующими свойствами. При введении прослойки из резины наблюдается повешение модуля вязкости, что подтверждает наличие демпфирующих свойств. Динамический механический анализ исходной стали показал, что напряжение, приложенное к образцу $\left(\sigma_{0}\right)$, составило $90 \%$ от условного предела текучести $\left(\sigma_{0,2}\right)$. При этом раскрытие петли механического гистерезиса не наблюдалось (рис. 6 a), что указывает на отсутствие каких-либо пластических деформаций стали 09Г2С при данном напряжении. При испытании композиционного материала напряжение составляло лишь $70 \%$ от условного предела текучести $\left(\sigma_{0,2}\right)$ металла. Это свидетельствует о том, что при деформировании разрывного образца в упругой области в условиях знакопеременного растяжения-сжатия пластической деформации и соответствующего раскрытия петли механического гистерезиса быть не должно. Однако фактически наблюдалось раскрытие петли механического гистерезиса при отсутствии пластической деформации (рис. 6 б). Это говорит о том, что изученный слоистый металлополимерный материал обладает достаточно высокими демпфирующими свойствами. 


\section{4. Заключение}

Испытания на ударную вязкость, проведенные при температурах +20 и $-60{ }^{\circ} \mathrm{C}$, показали, что при комнатной температуре характеристики ударной вязкости монолитной стали 09Г2С

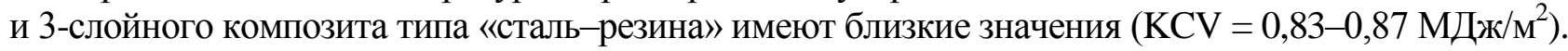
Однако при температуре испытаний $-60{ }^{\circ} \mathrm{C} 3$-слойный композиционный материал превосходит по величине ударной вязкости сталь 09Г2С примерно в 2 раза.

Проведенные знакопеременные циклические испытания по схеме растяжение-сжатие 3-слойного композита выявили на кривых циклического нагружения 3-слойного композита наличие разомкнутой петли механического гистерезиса, свидетельствующей о высокой демпфирующей способности данного материала. Применение резины в многослойных металлополимерных композитах, полученных методом холодного склеивания, позволяет придавать им повышенные демпфирующие свойства, оцениваемые с помощью комплекса таких показателей вибростойкости, как тангенс угла механических потерь $(\operatorname{tg} \delta)$, модуль упругости (Е') и модуль вязкости (E").

\section{Благодарность}

Авторы выражают благодарность сотруднику ИМАШ УрО РАН В.Г. Старкову за помощь в получении образиов композиционных материалов.

Работа выполнена с использованием оборудования ЦКП «Пластометрия» ИМАШ УрО в рамках государственного задания ИМАШ УрО РАН по теме № АAAA-А18118020790147-4 и при поддержке проекта УрО РАН № 18-9-1-20 (программа «Арктика»).

\section{Литература}

1. Формирование комплекса механических свойств и характеристик сопротивления разрушению сэндвич-композитов на основе стали 09Г2С и высокопрочной стали ЭП678 различной дисперсности / С. В. Гладковский, С. В. Кутенева, И. С. Каманцев, Р. М. Галеев, Д. А. Двойников // Diagnostics, Resource and Mechanics of materials and structures. - 2017. Iss. 6. - P. 71-90. - DOI: 10.17804/2410-9908.2017.6.071-090.

2. Layered Metal Composites with High Resistance to Brittle Fracture at Low Temperatures / S. V. Gladkovskii, I. S. Kamantsev, S. V. Kuteneva, D. A. Dvoynikov, A. V. Kuznetsov // AIP Conference Proceedings. - 2018. - Vol. 2053. - 020003. - DOI: 10.1063/1.5084349.

3. Gladkovsky S. V., Kuteneva S. V., Sergeev S. N. Microstructure and mechanical properties of sandwich copper/steel composites produced by explosive welding // Materials Characterization. 2019. - Vol. 154. - P. 294-303. - DOI: 10.1016/j.matchar.2019.06.008.

4. Chawla K. N. Composite Materials Science and Engineering. $-4^{\text {th }}$ ed. / Department of Materials Science and Engineering, USA. - Birmingham : The University of Alabama at Birmingham, 2019. - 557 p. - DOI: 10.1007/978-3-030-28983-6.

5. Каблов Е. Н. Инновационные разработки ФГУП «ВИАМ» ГНЦ РФ по реализации «Стратегических направлений развития материалов и технологии их переработки на период до 2030 года»// Авиационные материалы и технологии. - 2015. - № 1 (34). - С. 3-33. DOI: $10.18577 / 2071-9140-2015-0-1-3-33$.

6. Confirmation of the healing mechanism in a mendable EMAA-epoxy resin / S. Meure, R. J. Varley, Dong Yang Wu, S. Mayo, K. Nairn, S. Furman // European Polymer Journal. - 2012. Vol. 48. - P. 524-531. - DOI: 10.1016/j.eurpolymj.2011.11.021.

7. Chernikov S. A. Expansion of the suppression band of a vibroprotective system by a feedback dynamic damper // Journal of Machinery Manufacture and Reliability. - 2015. - Vol. 44, no. 5. - P. 439-444. - DOI: 10.3103/S1052618815050052. 
8. Пономарев Ю. К., Уланов А. М. Сравнение Российских и зарубежных виброизоляторов из проволочных демпфирующих материалов. // Известия Самарского научного центра Российской академии наук. - 2009. - № 3. - С. 214-218.

9. Типалин С. А., Сапрыткин Б. Ю. Шпунькин Н. Ф. Краткий обзор многослойных листовых деформируемых материалов, используемых для защиты от шума // Известия МГТУ «МАМИ». - 2012. - Т. 2, № 2 (14). - С. 194-199.

10. Колодкин М. Н., Зайцев А. А. Перспективные конструкции пути в метрополитене. // Транспорт Российской федерации. - 2012. - № 40-41. - С. 74-76.

11. Вербилов А. Ф., Ковалёв В. В., Ульрих С. А. Нелинейные колебательные процессы в динамике гусеничного движителя с резинометаллическими шарнирными соединениями // Известия Самарского научного центра Российской академии наук. - 2018. - № 6. - С. 243-247.

12. Подготовка поверхности алюминиевого сплава В-1469 перед применением в составе слоистого гибридного материала / В. В. Антипов, Д. В. Чесноков, И. А. Козлов, И. А. Волков, А. П. Петрова // Труды ВИАМ. - 2018. - № 64. - С. 59-65. - DOI: 10.18577/2307-6046-2018-04-59-65.

13. Влияние состава вибропоглощающих материалов на коэффициент механических потерь / В. А. Сагомонова, В. И. Кислякова, Т. Ю. Тюменева, В. А. Большаков // Труды ВИАМ. 2015. - № 10. - С. 63-69. - DOI: 10.18577/2307-6046-2015-0-10-10-10.

14. Новые вибропоглощающие материалы / Ю. В. Сытый, В. А. Сагомонова, В. И. Кислякова, В. А. Большаков // Авиационные материалы и технологии. - 2012. - № 2. - С. 51-54.

15. Пономарев Ю. К., Уланов А. М. Сравнение Российских и зарубежных виброизоляторов из проволочных демпфирующих материалов // Известия Самарского научного центра Российской академии наук. - 2009. - № 3. - С. 214-218.

16. Черкасов В. Д., Соломатов В. И., Фомин Н. Е. Упругие и демпфирующие свойства конструкционных металлических материалов. Вибропоглощающие композиционные материалы. - Саранск : Изд-во Мордовского ун-та, 2001. - 95 с.

17. Embury J. D., Petch N. J, Wright E. S. Fracture of mild steel laminates // Transactions of the Society of Mining Engineers of AIME. - 1967. - Vol. 239 (1). - P. 114-18.

18. Fracture Behavior and Delamination Toughening of Molybdenum in Charpy Impact Tests / K. Babinsky, S. Primig, W. Knabl, A. Lorich, R. Stickler, H. Clemens // Journal of the Minerals Metals \& Materials Society. - 2016. - Vol. 68, iss. 11. - P. 2854-2863. - DOI: 10.1007/s11837016-2075-y. 